\title{
Tubercular monoarthritis of the glenohumeral joint in a non-endemic region: Vancouver, Canada
}

\author{
Tyler Murray (1)
}

Department of Internal Medicine, The University of British Columbia Faculty of Medicine, Vancouver, British Columbia, Canada

\section{Correspondence to}

Dr Tyler Murray;

t.murray@mail.utoronto.ca

Accepted 15 October 2020

\section{DESCRIPTION}

A previously healthy 24 -year-old man presented to an emergency department in Vancouver, Canada with a 4-month history of atraumatic, chronic progressive, monoarticular right shoulder pain, with restricted range of motion. He was otherwise healthy withno chronic medical conditions, no previous surgeries and was taking no regular medications. He immigrated to Canada 2 years earlier in 2018 from Andra Pradesh state in South Eastern India. Since immigrating to Canada he made several return trips to India including a 1 month period in 2019.

Physical examination revealed restricted abduction, external rotation at the shoulder with moderate deltoid and bicep muscle wasting. On review of systems, the only associated symptom was $5 \mathrm{~kg}$ of unintentional weight loss despite a preserved appetite. He had no recurrent fevers, night sweats, lymphadenopathy or respiratory symptoms. He was not started empirically on antimicrobial therapy on admission due to a lack of septic clinical features.

The initial musculoskeletal ultrasound showed severe tenosynovitis, glenohumeral joint erosions with a small effusion not amenable to bedside arthrocentesis. Laboratory investigations showed a modest neutrophilic leukocytosis and mildly elevated C-reactive protein (CRP) of 26 , a negative rheumatoid factor, anti-citrullinated protein antibody (anti-CCP) and anti-nuclear antibody (ANA) panel. A chest X-ray was normal with no evidence of granulomatous disease. The infectious disease and rheumatology services were consulted. The provisional diagnosis at this stage, given local epidemiology and findings on preliminary imaging was a mono-articular arthritis with a broaddifferential diagnosis including auto-immune, inflammatory and infectious etiologies. The Infectious Disease team was then consulted with combined recommendations to pursue an MSK MRI, serum IGRA given his receipt of the BCG vaccine and possibly a synovial biopsy.

An interventional radiology-guided arthrocentesis and biopsy of the glenoid articular cartilage were completed; the initial bacterial cultures, acid-fast bacilli smear, cytology and crystal microscopy were negative. The polymorphonuclear cell count was minimal. The subsequent musculoskeletal MRI showed an interosseous abscess with infarct of the humeral head, suspicious of chronic infection without malignant features (figures 1 and 2). The articular cartilage biopsy was then sent for TB-PCR which resulted positive for Myocobacterium Tuberculosis, confirming the diagnosis oftubercular mono-arthritis. ${ }^{1}$ Orthopaedics surgery was consulted; the preference was medical

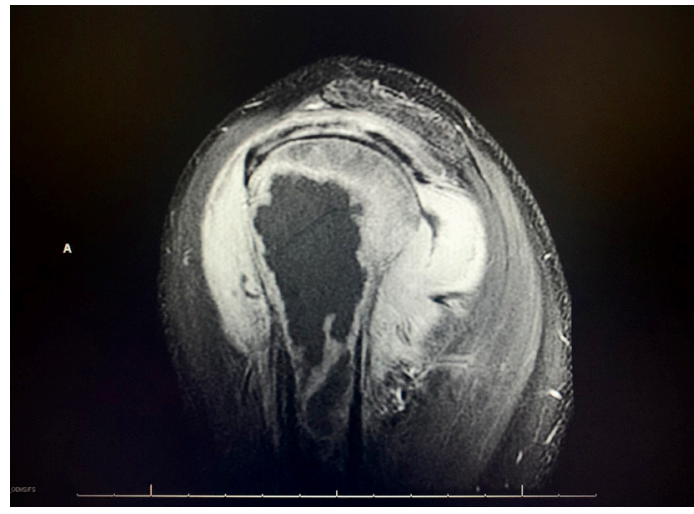

Figure 1 Right shoulder MRI T1 signal sagittal view illustrating interosseous abscess and cortical infarct of the humeral head.

treatment with antimicrobial therapy prior to surgical intervention. The patient was started initially on rifampin, isoniazid, pyrazidamide and ethambutol due to antimicrobial resistance rates and planned 9 months of treatment. He was discharged from the hospital with infectious disease follow-up.

The early diagnosis and treatment in the emergency department of acute septic arthritis is crucial to prevent sepsis, joint destruction, the need for surgical intervention and death. Coexistence of acute gout and septic arthritis is common, which often warrants empiric antibiotic coverage until the definitive diagnosis is made. Physical examination and history are often not enough to make the diagnosis. ${ }^{2}$ Useful diagnostic tests include radiographs of affected and contralateral joint, synovial fluid analysis for culture, gram stain, crystals and cell count. ${ }^{2-7}$ Gout and bacterial septic arthritis

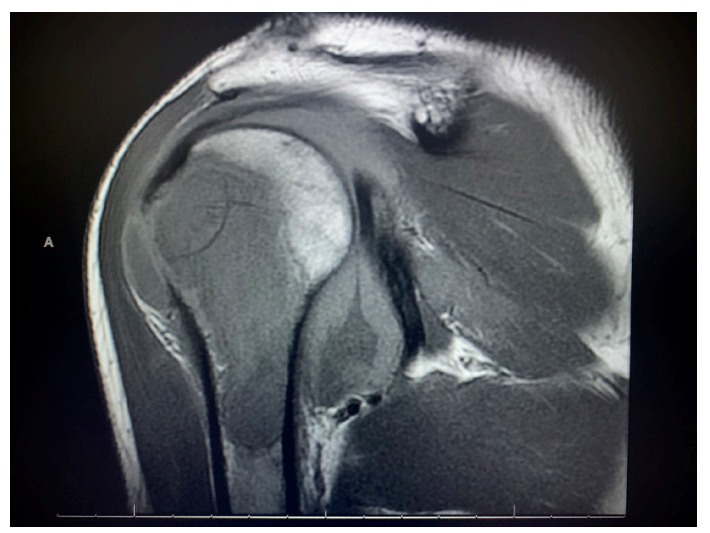

Figure 2 Right shoulder MRI T2 signal sagittal view illustrating interosseous abscess and cortical infarct of the humeral head. 
response to initial treatment can be diagnostic. ${ }^{23}$ Serum inflammatory markers such as ESR and CRP are non-specific and not helpful differentiators. ${ }^{4}$ Synovial fluid smear sensitivity for acid-fast bacilli in true cases of tubercular arthritis is low (20\%-40\%), ${ }^{5}$ requiring a high index of suspicion and usually a synovial tissue biopsy for diagnosis. The synovial biopsy should be cultured and in capable laboratories, sent for TB-PCR as was required in our case to confirm the diagnosis.

The prevalence of monarthritis diagnoses in a sample of studies conducted in Canada and USA are listed here in descending order from the most common: undetermined (16\%-36\%), gout (15\%$27 \%)$, septic arthritis (8\%-27\%), osteoarthritis (5\%-17\%), rheumatoid arthritis (11\%-16\%), trauma (11\%), lupus (7\%), psoriatic arthritis (5\%), reactive arthritis (5\%), pseudogout (3\%), spontaneous haemarthrosis (3\%), aseptic necrosis $(2 \%)$ and TB $(2 \%$, one case in one study). ${ }^{24-8}$ Approximately $10 \%$ of extrapulmonary TB $(1 \%-3 \%$ of total TB cases) affect the joints and bones, with the most common manifestation site being the spine; if peripheral joints are involved, it is typically a monarthritis of the knee or hip (85\%), load-bearing joints. ${ }^{5910}$ It is rare to see the upper extremity joints involved. Very occasionally, the TB arthritis is oligoarticular causing diagnostic confusion with other inflammatory arthritis. ${ }^{510}$

The differential diagnosis of acute monarthritis in a TB endemic region, such as India for example, is similar to North America with septic arthritis and gout being the most common diagnoses. 5811 However, in subacute or chronic monarthritis, the most common causes are $\mathrm{TB}$, fungal infections, followed then by autoimmune

\section{Learning points}

- Mycobacterium tuberculosis should be included in any differential diagnosis of monarthritis even in non-endemic regions when your patient has epidemiologic risk factors until a definitive diagnosis is made. Delays in diagnosis are common and associated with increased morbidity and mortality.

- If there is any clinical suspicion for tuberculosis infection, persistent workup will be necessary to confirm or refute the diagnosis including a synovial biopsy with smear, culture and PCR for M. tuberculosis.

- When tuberculosis infects the peripheral joints, the clinical presentation is more typically monoarticular in load-bearing joints as opposed to disseminated infection or polyarticular involvement. conditions rheumatoid arthritis, spondyloarthropathies and reactive arthritis. $^{511}$

Correction notice This article has been corrected since it was published Online. The acknowledgement statement has been updated with "I would like to acknowledge the involvement of the following staff physicians in this clinical case: Dr Sarah Ickowicz who provided overall care to the patient as the internal medicine attending and Dr Jon Kelsall who provided specialist consultant opinions that helped lead to the diagnosis." There are some corrections in the first, second and fourth paragraphs.

Acknowledgements (1) University of British Columbia, Internal Medicine Residency Program. (2) Vancouver General Hospital. (3) St Paul's Hospital. (4) Vancouver Coastal Health Authority. The author would also like to acknowledge the involvement of the following staff physicians in this clinical case: Dr Sarah Ickowicz who provided overall care to the patient as the internal medicine attending and Dr Jon Kelsall who provided specialist consultant opinions that helped lead to the diagnosis.

Contributors TM is the sole contributor, currently employed as an Internal Medicine Resident Physician through Vancouver Coastal Health Authority affiliated with the University of British Columbia, Vancouver Program.

Funding The authors have not declared a specific grant for this research from any funding agency in the public, commercial or not-for-profit sectors.

Competing interests None declared.

Patient consent for publication Obtained.

Provenance and peer review Not commissioned; externally peer reviewed.

ORCID iD

Tyler Murray http://orcid.org/0000-0002-8773-1329

\section{REFERENCES}

1 Al-Sayyad MJ, Abumunaser LA. Tuberculous arthritis revisited as a forgotten cause of monoarticular arthritis. Ann Saudi Med 2011;31:398-401.

2 Ma L, Cranney A, Holroyd-Leduc JM. Acute monoarthritis: what is the cause of my patient's painful swollen joint? CMAJ 2009;180:59-65.

3 Margaretten ME, Kohlwes J, Moore D, et al. Does this adult patient have septic arthritis? JAMA 2007;297:1478-88.

4 Jeng GW, Wang CR, Liu ST, et al. Measurement of synovial tumor necrosis factoralpha in diagnosing emergency patients with bacterial arthritis. Am J Emerg Med 1997:15:626-9.

5 Malaviya AN, Kotwal PP. Arthritis associated with tuberculosis. Best Pract Res Clin Rheumatol 2003;17:319-43.

6 Parker JD, Capell HA. An acute arthritis clinic--one year's experience. Br J Rheumatol 1986;25:293-5.

7 Shmerling RH, Delbanco TL, Tosteson AN, et al. Synovial fluid tests. what should be ordered? JAMA 1990;264:1009-14.

8 Freed JF, Nies KM, Boyer RS. Acute monoarticular arthritis. JAMA 1980;243:2314-6.

9 Sequeira W, Co H, Block JA. Osteoarticular tuberculosis: current diagnosis and treatment. Am J Ther 2000;7:393-8.

10 Sharma SK, Mohan A. Extrapulmonary tuberculosis. Indian J Med Res 2004; 120:316-53.

11 Cuéllar ML, Silveira LH, Espinoza LR. Fungal arthritis. Ann Rheum Dis 1992;51:690-7.

Copyright 2021 BMJ Publishing Group. All rights reserved. For permission to reuse any of this content visit

https://www.bmj.com/company/products-services/rights-and-licensing/permissions/

BMJ Case Report Fellows may re-use this article for personal use and teaching without any further permission.

Become a Fellow of BMJ Case Reports today and you can:

- Submit as many cases as you like

- Enjoy fast sympathetic peer review and rapid publication of accepted articles

- Access all the published articles

Re-use any of the published material for personal use and teaching without further permission

Customer Service

If you have any further queries about your subscription, please contact our customer services team on +44 (0) 2071111105 or via email at support@bmj.com.

Visit casereports.bmj.com for more articles like this and to become a Fellow 